\title{
Long term follow up after HCV cure with direct acting antivirals - review of the literature
}

\author{
Andreea Ruxandra Cazan ${ }^{1,2}$, George Sebastian Gherlan ${ }^{1,2}$, Raluca Mihaela Dîrtu',2, \\ Simin Aysel Florescu ${ }^{1,2}$, Anca Cristiana Oprea ${ }^{1,2}$, Emanoil Ceausu ${ }^{1,2}$, \\ Petre lacob Calistru',2 \\ 1"Carol Davila" University of Medicine and Pharmacy, Bucharest, Romania \\ 2"Dr. Victor Babes" Clinical Hospital of Infectious and Tropical Diseases, Bucharest, Romania
}

\begin{abstract}
The era of oral direct antivirals has completely changed the picture of chronic hepatitis $C$. The rates of sustained virological response overpassed the $90 \%$ percentage, but new challenges are coming: the persisting liver disease, the complications on long term, the follow up. The new treatment came with the advantage of increased number of patients that can be treated (cirrhotic patients including the ones with advanced disease, the co-infected patients HCV-HIV, the patients with end stage renal disease). The experience with these drugs is relatively short, but there are some general recommendations for the post-treatment surveillance. This review discusses the recommended follow-up and the clinical findings in patients, after obtaining SVR (sustained virological response).
\end{abstract}

Keywords: HCV chronic infection, DAAs, hepatocellular carcinoma

\section{INTRODUCTION}

It is generally accepted that patients with chronic HCV infection who achieve sustained virological response (SVR) after treatment have a better prognosis regarding long term complications and survival. However, in 1999, professor Poynard published a paper concerning the impact of interferon treatment that supports the possibility of aggravation of fibrosis after the HCV cure (1). According to another study published in 2002 by the same author, there were six factors independently associated with fibrosis regression after bitherapy (Pegylated interferon and ribavairin): low fibrosis score before treatment, obtaining SVR, young age
( $<40$ years), body mass index $<27 \mathrm{~kg} / \mathrm{m}^{2}$, absence or low activity before treatment and viral load $<3.5$ millions copies/ml (2). In the era of the new antivirals, HCV cure has become a normal expectation. Despite curing the infection, these patients need long term follow-up, especially those with an advanced liver disease (with advance fibrosis) and the coinfected patients (with HIV or HBV). The patients with cirrhosis are predisposed to develop hepatocellular carcinoma, as for the those without cirrhosis the prognosis lies in the HCV associated comorbidities (obesity, diabetes mellitus type 2). This review discusses the recommended follow-up and the clinical findings in patients, after obtaining SVR (sustained virological response). 


\section{TREATMENT GOAL}

The primary end-point of the antiviral treatment is curing the infection, obtaining an SVR (sustained virological response). EASL (European Association for the Study of the Liver) guidelines consider the infection cure an undetectable HCV RNA at 48 weeks after the treatment was ended. The Romanian National Authorities consider an undetectable HCV RNA at week 12 as a marker of HCV cure (the cost of viral load detection is supported at the end of treatment and at 12 weeks after EOT). A study published in 2015 regarding sofosbuvir based regimens, showed a concordance for SVR at 12 and 24 weeks, concluding that SVR at 12 weeks can be consider a marker of cure in clinical practice (3). The HVC ARN clearance is associated with the disappearance of the infection related immune responses. Even so, a research group detected the presence of HCV RNA in peripheral mononuclear cells after 9 years of SVR, but without markers of increased risk of liver disease (4). Another study showed a rate of late relapse (4 of 97 patients with occult infection) using high sensitive HCV ARN detection, but without significant liver disease after more than 10 years of follow-up) (5).

\section{CIRRHOSIS RELATED MORBIDITY AND MORTALITY (INCLUDING HCC)}

Regression of fibrosis is associated with decrease of liver related complications. The liver biopsy remains the gold standard for fibrosis staging, but nowadays noninvasive tests are commonly used in daily practice to evaluate disease severity. Despite their popularity, the serological tests didn't proved to obtain accurate results for residual fibrosis in nonviremic patients, and liver biopsy remains the optimal option (6). Similar with serological tests, Transient Elastography (Fibroscan) cannot be used as a predictor for liver fibrosis course after the SVR, and the biopsy still the only reliable approach (7).

Studies performed in order to assess liver fibrosis after the treatment, using liver biopsies before and after the treatment, could not conclude a definite amelioration of pathological findings in these patients (persistent portal inflammation and sinusoidal capillarization) (8).
A study published in 2017 on $41 \mathrm{HCV}$ patients (with compensated advanced chronic liver disease) treated with oral antivirals found that liver and spleen stiffness measurement decrease rapidly, but this is probably a consequence of reduction of inflammation (9).

Another recent study evaluated liver stiffness amelioration in 143 patients, using transient elastography and biological scores (FIB-4 and APRI) at specific intervals (baseline, week 24, week 96). In this study the majority of patients with SVR had improved liver stiffness values, in the long term follow-up, but a proportion of patients developed progression of fibrosis. Periodic evaluation by noninvasive tests seems to be rationale in this context (10).

Curing HCV is associated with an important decrease of related mortality and morbidity, but in patients with advanced fibrosis ( $>$ F3, including cirrhosis), the regular follow-up for hepatocellular carcinoma is mandatory, also the endoscopic screening for esophageal varices. The patients with severe fibrosis at baseline should be carefully screened for hepatocellular carcinoma indefinitely.

After SVR, the risk of HCC decreases but still high compared with the general population (overall incidence of $0.33 \%$ per year). In a large cohort of $\mathrm{HCV}$ infected patients who received antiviral treatment the annual risk for patients with cirrhosis was $1.39 \%$, being higher in older patients ( $>60$ years of age) or who had diabetes (11).

In a follow-up study, three noncirrhotic patients (of 97 surveilled) developed hepatocellular carcinoma at 9 years after the EOT (5).

Concerning the risk of recurrence of hepatocellular carcinoma related to antiviral treatment, a large study performed in France (French ANRS cohort with more than 6000 patients - Agence Nationale de Recherche sur le Sida et les hépatites virales) proved there is no evidence of higher risk in these patients (the rate of recurrence was similar in treated and untreated patients) (12). This study was performed secondary to the alarm signal raised by previous papers who mentioned a risk of recurrence of HCC, despite very high rate of SVR after DAAs (direct acting activirals) $(13,14)$.

Another major problem associated with chronic liver disease in hepatitis $\mathrm{C}$ is the need for liver transplantation. With the introduction of the new 
antivirals, some patients were delisted because of the improvement of the MELD score after the treatment. Despite this improvement, patients with end stage liver disease will eventually need a liver transplantation in the future. The main controversy concerning these patients was the moment of treatment (before or after the transplantation). The interferon-based regimen used before had serious adverse effects, so it was contraindicated in patients with decompensated liver disease, but the DAAs are well tolerated and can be started before liver transplantation. Obtaining a SVR will not change dramatically the course of the disease, but will prolong the interval to transplant. In the era of the new antivirals, the survival after liver transplantation improved, being similar with the one of the HBV recipients.

\section{COINFECTIONS}

HIV presence should not be considered a barrier for successful treatment of $\mathrm{HCV}$ infection. This particular population has frequently advanced liver disease, but some antivirals regimens are very effective and well tolerated (sofosbuvir/ledipasvir and sofosbuvir/simeprevir) (15).

The progression was observed in patients with a high HIV load (persistent replication under antiretroviral treatment) or after prolonged exposure to protease inhibitors. The periodic assessment of liver disease (including liver fibrosis) and HCC screening is warranted in these patients (16). Achievement of SVR reduces the risk of decompensation and the liver related mortality in the coinfected patients, but despite the apparent improvement of fibrosis, in some patients the liver disease progress.

Concerning the HBV-HCV coinfection, the recommendation is to treat the dominant infection, which is usually the HCV. The HCV new treatment is very efficient, but this category of patients is at risk to develop a reactivation of $\mathrm{B}$ virus. The reactivation of the $\mathrm{B}$ virus is partially explained by the sudden lack of competition between the two viruses during the HCV clearance. Patients with a positive $\mathrm{HBsAg}$, with a replicative virus (detectable VHB DNA) should be treated until the confirmation of an SVR for HCV at 12 weeks. The patients with undetectable VHB DNA should be carefully monitored (viral load, ALT) until they had the confirmation for SVR at 12 weeks. Patients with negative $\mathrm{HBs} \mathrm{Ag}$ and a positive $\mathrm{HBcAb}$ should be also monitored (viral load, ALT) and treated if ALT increases or HBV DNA becomes detectable during the HCV treatment (17).

\section{COMORBIDITES}

In patients with no cirrhosis who achieved a sustained virological response, the prognosis of liver disease would be influenced by the presence of comorbidities, like diabetes or obesity.

The alcohol consumption also can change the course of the disease, first by decreasing the success rate of the antiviral treatment, but also by increasing the severity of the liver disease after.

The presence of NASH (non alcoholic steatohepatitis) is associated with the progression of the disease and cirrhosis, after the HCV clearance, if the metabolic factors are not removed.

Apparently, noncirrhotic patients who achieved SVR are prone to an unexplained increased liver related morbidity, up to six times compared with the general population (18).

The serum GGT (gamma-glutamyl tranferase) is a surrogate marker of liver injury, but is also associated with cardiovascular morbidity and mortality, mainly in patients with coronary artery disease and with type 2 diabetes (19). Serum GGT is also a biomarker correlated with hepatocellular carcinoma in non-cirrhotic patients with SVR (20).

\section{RELAPSING AND REINFECTION}

In the majority of cases successfully treated with DAAs, in which the HCV RNA is detectable after a period of time, the cause is reinfection. The viral reactivation after suppression of HCV RNA during the DAAs treatment is highly associated with hepatocellular carcinoma development, especially in patients with compensated liver disease, suggesting a more aggressive outcome (21).

The posibility of reinfection is high in patients with persistent risk of contamination like IV drug users or men who have sex with men. Regarding the IV drug users, the risk of reinfection is decreased among those who receive opioid-agonist therapy (22). Reinfection rates in real life can be 
underestimated, because only the phylogenetic analysis can discriminate the reinfection from the relapse.

\section{UNPREDICTED OUTCOMES}

HCV cure after the treatment with direct acting antivirals was observed to be associated with weight gain in an important percent of patients (44\% in a recent study), this secondary outcome being predominantly seen in patients younger than 60 years (23). The mechanism of weight gain is still unexplained, but can be secondary to patient enthusiasm (no more diet regimen to be followed compared with the period when they had hepatitis $\mathrm{C}$, an important burden that imposed specific attention). The weight gain can become a risk factor for these patients, in addition to other comorbidities, like diabetes. Not to mention that already a great propor- tion of these patients are obese and have liver steatosis. A high BMI is also associated with development of liver cirrhosis, independently of the treatment response.

\section{CONCLUSIONS}

The well known target of World Health Organization is the eradication of $\mathrm{HCV}$ infection in the next decades. But above this goal, all the research studies published regarding the outcome in these patients underline the importance of long term surveillance. Curing $\mathrm{HCV}$ is not equal with curing the disease. We cannot predict yet all the effects of antiviral therapy or the course of the disease after viral clearance. It is important to increase awareness between the specialists, but also between patients, to continue periodic visits of follow-up.

\section{REFERENCES}

1. Rodolphe Sobesky, Philippe Mathurin, Frederic Charlotte, Joseph Moussalli, Martine Olivi, Michel Vidaud, Vlad Ratziu, Pierre Opolon, Thierry Poynard, Modeling the impact of interferon alfa treatment on liver fibrosis progression in chronic hepatitis C: A dynamic view, Gastroenterology, February 1999Volume 116, Issue 2, Pages 378-386

2. Poynard T, McHutchison J, Manns M, Trepo C, Lindsay K, Goodman $\mathrm{Z}$, Ling MH, Albrecht J. Impact of pegylated interferon alfa-2b and ribavirin on liver fibrosis in patients with chronic hepatitis $\mathrm{C}$. Gastroenterology. 2002 May;122(5):1303-13.

3. Yoshida EM, Sulkowski MS, Gane EJ, Herring RW Jr, Ratziu V, Ding X, Wang J, Chuang SM, Ma J, McNally J, Stamm LM, Brainard DM, Symonds WT,McHutchison JG, Beavers KL, Jacobson IM, Reddy KR, Lawitz E., Concordance of sustained virological response 4, 12, and 24 weeks post-treatment with sofosbuvir-containing regimens for hepatitis C virus. Hepatology, 2015 Jan; 61(1):41-5. doi: 10.1002/ hep.27366. Epub 2014 Nov 24

4. Hedenstierna M, Weiland O, Brass A, Bankwitz D, Behrendt $P$, Uhnoo I, Aleman S, Cardell K, Fryden A, Norkrans G, Eilard A, Glaumann H, Pietschmann T, Sällberg M, Brenndörfer ED. Long-term follow-up of successful hepatitis $C$ virus therapy: waning immune responses and disappearance of liver disease are consistent with cure. Aliment Pharmacol Ther. 2015 Mar;41(6):532-43. doi: 10.1111/ apt.13096. Epub 2015 Jan 28

5. Lybeck C1, Brenndörfer ED2, Sällberg M2, Montgomery SM3,4,5, Aleman S6,7, Duberg AS1., Long-term follow-up after cure from chronic hepatitis $C$ virus infection shows occult hepatitis and a risk of hepatocellular carcinoma in noncirrhotic patients. Eur J Gastroenterol Hepatol. 2018 Nov 19. doi: 10.1097/MEG.0000000000001316.

6. Roberta D'Ambrosio, Elisabetta Degasperi, Alessio Aghemo, Mirella Fraquelli, Pietro Lampertico, Maria Grazia Rumi, Floriana Facchetti, Eleonora Grassi, Giovanni Casazza, William Rosenberg, Pierre Bedossa, and Massimo Colombo, Serological Tests Do Not Predict Residual Fibrosis in Hepatitis C Cirrhotics with a Sustained Virological Response to Interferon., Journal List PLoS One v.11(6); 2016

7. D'Ambrosio R, Aghemo A, Fraquelli M, Rumi MG, Donato MF, Paradis V, Bedossa P, Colombo M., The diagnostic accuracy of Fibroscan for cirrhosis is influenced by liver morphometry in HCV patients with a sustained virological response. J Hepatol. 2013
Aug;59(2):251-6. doi: 10.1016/j.jhep.2013.03.013. Epub 2013 Mar 23.

8. D'Ambrosio R, Aghemo A, Rumi MG, Ronchi G, Donato MF, Paradis V, Colombo M, Bedossa P., A morphometric and immunohistochemical study to assess the benefit of a sustained virological response in hepatitis C virus patients with cirrhosis. Hepatology. 2012 Aug;56(2):532-43. doi: 10.1002/hep.25606. Epub 2012 Jul 2

9. Pons M, Santos B, Simón-Talero M, Ventura-Cots M, Riveiro-Barciela M, Esteban R, Augustin S, Genescà J. Rapid liver and spleen stiffness improvement in compensated advanced chronic liver disease patients treated with oral antivirals., Therap Adv Gastroenterol. 2017 Aug;10(8):619-629. doi: 10.1177/1756283X17715198. Epub 2017 Jun 27.

10. Pietsch V, Deterding K, Attia D, Ringe KI, Heidrich B, Cornberg M, Gebel M, Manns MP, Wedemeyer H, Potthoff A. Long-term changes in liver elasticity in hepatitis $C$ virus-infected patients with sustained virologic response after treatment with direct-acting antivirals. United European Gastroenterol J. 2018 Oct;6(8):1188-1198. doi: 10.1177/2050640618786067. Epub 2018 Jun 27.

11. El-Serag HB, Kanwal F, Richardson P, Kramer J. Risk of hepatocellular carcinoma after sustained virological response in Veterans with hepatitis C virus infection. Hepatology. 2016 Jul;64(1):130-7. doi: 10.1002/hep.28535. Epub 2016 Apr 19.

12. ANRS collaborative study group on hepatocellular carcinoma (ANRS CO22 HEPATHER, CO12 CirVir and CO23 CUPILT cohorts). Electronic address: stanislas.pol@aphp.fr, Lack of evidence of an effect of direct-acting antivirals on the recurrence of hepatocellular carcinoma: Data from three ANRS cohorts. J Hepatol. 2016 Oct;65(4):734-740. doi: 10.1016/j.jhep.2016.05.045. Epub 2016 Jun 7.

13. Conti F, Buonfiglioli F, Scuteri A, Crespi C, Bolondi L, Caraceni P, Foschi FG, Lenzi M, Mazzella G, Verucchi G, Andreone P, Brillanti S. Early occurrence and recurrence of hepatocellular carcinoma in HCV-related cirrhosis treated with direct-acting antivirals. J Hepatol. 2016 Oct;65(4):727-733. doi: 10.1016/j.jhep.2016.06.015. Epub 2016 Jun 24.

14. Reig $M$, Mariño Z, Perelló $C$, Iñarrairaegui $M$, Ribeiro $A$, Lens $S$, Díaz A, Vilana R, Darnell A, Varela M, Sangro B, Calleja JL, Forns X, Bruix $J$. Unexpected high rate of early tumor recurrence in patients with $\mathrm{HCV}$-related HCC undergoing interferon-free therapy. $\mathrm{J}$ Hepatol. 
2016 Oct;65(4):719-726. doi: 10.1016/j.jhep.2016.04.008. Epub 2016 Apr 13.

15. Hawkins C, Grant J, Ammerman LR, Palella F, Mclaughlin M, Green $\mathrm{R}$, Mcgregor D, Stosor V. High rates of hepatitis $\mathrm{C}$ virus (HCV) cure using direct-acting antivirals in HIV/HCV-coinfected patients: a real-world perspective. J Antimicrob Chemother. 2016 Sep;71(9):2642-5. doi: 10.1093/jac/dkw203. Epub 2016 Jun 20.

16. Labarga P1, Fernandez-Montero JV, de Mendoza C, Barreiro P, Pinilla J, Soriano V., Liver fibrosis progression despite HCV cure with antiviral therapy in HIV-HCV-coinfected patients. Antivir Ther. 2015; 20(3):329-34. doi: 10.3851/IMP2909. Epub 2014 Nov 5.

17. Ann T. Ma, Jordan J. Feld Hepatitis B Reactivation With Hepatitis C Treatment: Bringing Some Clarity to the Black Box, Gastroenterology, March 2018Volume 154, Issue 4, Pages 795-798

18. Innes HA, Hutchinson SJ, Allen S, Bhattacharyya D, Bramley P, Delahooke TE, Dillon JF, Forrest E, Fraser A, Gillespie R, Goldberg DJ, Kennedy N,McDonald S, McLeod A, Mills PR, Morris J, Hayes P; Hepatitis C Clinical Database Monitoring Committee. Excess liver-related morbidity of chronic hepatitis $C$ patients, who achieve a sustained viral response, and are discharged from care. Hepatology. 2011 Nov;54(5):1547-58. doi: 10.1002/hep.24561

19. Sluik D, Beulens JW, Weikert C, van Dieren S, Spijkerman AM, van $\operatorname{der} A D$, et al. Gamma-glutamyltransferase, cardiovascular disease and mortality in individuals with diabetes mellitus. Diabetes Metab Res Rev. 2012; 28: 284-8. doi: 10.1002/dmrr.2261
20. Huang CF, Yeh ML, Tsai PC, Hsieh MH, Yang HL, Hsieh MY, Yang JF, Lin ZY, Chen SC, Wang LY, Dai CY, Huang JF, Chuang WL, Yu ML., Baseline gamma-glutamyl transferase levels strongly correlate with hepatocellular carcinoma development in non-cirrhotic patients with successful hepatitis C virus eradication. J Hepatol. 2014 Jul;61(1):67-74. doi: 10.1016/j.jhep.2014.02.022. Epub 2014 Mar 5.

21. L. Cavalletto, C. Aliberti, A. Romano, A. Biasiolo, P. Pontisso, P. Angeli, L. Chemello, Relapse after direct-acting antivirals (DAAs) in cirrhotic patients with hepatitis $\mathrm{C}$ is highly related to development of liver cancer., Journal of Hepatology, 2017Volume 66, Issue 1, Supplement, Page S536

22. Rossi C, Butt ZA, Wong S, Buxton JA, Islam N, Yu A, Darvishian M, Gilbert M, Wong J, Chapinal N, Binka M, Alvarez M, Tyndall MW, Krajden M,Janjua NZ; BC Hepatitis Testers Cohort Team. Hepatitis C virus reinfection after successful treatment with direct-acting antiviral therapy in a large population-based cohort. J Hepatol. 2018 Nov;69(5):1007-1014. doi: 10.1016/j.jhep.2018.07.025. Epub 2018 Aug 22.

23. Schlevogt B1, Deterding K1, Port K1, Siederdissen CHZ1, Sollik L1, Kirschner J1, Mix C1, Manns MP1,2,3, Cornberg M1,3, Wedemeyer $\mathrm{H} 1,2,3$., Interferon-free cure of chronic Hepatitis $\mathrm{C}$ is associated with weight gain during long-term follow-up. Z Gastroenterol. 2017 Sep;55(9):848-856. doi: 10.1055/s-0043-112656. Epub 2017 Sep 12. 